1. M Phil, Senior Instructor Department of Community Health Sciences,

Fatima Memorial College of Medicine and Dentistry

2,3,4,5,6

$4^{\text {th }}$ Year MBBS Students, Department of Community Health

Sciences,

Fatima Memorial College of

Medicine and Dentistry

Correspondence Address: Dr. Naureen Omar 33-H Gulberg 3, Lahore, Pakistan naureen_omar@yahoo.com

Article received on: 06/06/2015

Accepted for publication: 27/10/2015

Received after proof reading: 00/00/0000

\section{HEALTH CARE FACILITIES AT SCHOOL; PERCEPTION OF STUDENTS}

\begin{abstract}
Dr. Naureen Omar ${ }^{1}$, Rameeshey Khan², Faizan Farooq ${ }^{3}$, Humera Karim4, Muhammad Ayoub ${ }^{5}$,
\end{abstract} Ushna Habib 6

ABSTRACT: Schools should pertain to a comprehensive system to deal with day to day emergencies, as children spend more than six hours at school and are liable to suffer from injuries and illnesses. Objectives: This study was conducted with the objective of assessing the experiences of students regarding healthcare management especially first aid patterns at school. Study Design: Cross sectional study. Setting: Study was conducted on 50 students enrolled from ten identified public and private schools of Lahore Period: Six months. Methods: In depth interviews were conducted on students from classes 6-10 who had suffered from an injury or illness during school hours within the last six months. Results: In these 50 students the most common injury were fractures and dislocations (15), most common illness was fever (19). Majority (41) were managed at schools with a first aid facility and provision of sick rooms (28). Teachers were the main healthcare providers in private schools (17), as compared to public schools (9). Lack of properly trained health professionals was observed; only 7 out of 50 schools had employed nurses. Health education regarding hand washing, personal hygiene, dengue prevention was being provided in (45) schools. Conclusion: This study highlights the importance of provision of first aid services at school and the need to train teachers regarding basic life support. Implementation of the existing school health program needs to be emphasized in all schools of Lahore.

Key words: $\quad$ School health, First aid patterns at school, Injuries/lllnesses at school.

Article Citation: Omar N, Khan R, Farooq F, Karim H, Ayoub M, Habib U. Health care facilities at school; perception of students. Professional Med J 2015;22(12):15461549.DOI: 10.17957/TPMJ/15.2963

\section{INTRODUCTION}

Health status and learning capacity are invariably linked. ${ }^{1}$ School health policies around the world aim to ensure optimum positive health of school going children. School healthcare system can be defined as a coordinated system that ensures a continuum of care from school to home, to community, healthcare provider and back ${ }^{2}$, thus highlighting the importance of provision and implementation of school health services.

WHO's Global School Health Initiative (GSHI) launched in 1995, seeks to improve the health of students, student personnel, families and other members of the community through schools around the world. ${ }^{3}$ Australia, Canada, Ireland and Singapore are leading examples of exemplary school health systems. In Nigeria and India non-profit organizations are also dedicated to improving the health of adolescents. ${ }^{4}$
Pakistan being a developing country not only requires to strengthen the school health system but also needs to ensure the provision and implementation of a comprehensive school health program. In Pakistan, during 2005-2007, the National Commission for Human Development (NCHD) launched an integrated school health program with funding provided by the Bill and Melinda Gates Foundation. It was initially conducted in 16 districts of Pakistan; 03 from NWFP (Khyber PakhtunKhwa), 05 from Punjab, 04 from Sindh and 04 from Baluchistan, covering 115 primary schools and training of 69,224 teachers was done thus benefitting 2.17 million students. ${ }^{5}$ Later on, in 2010, the Ministry of Education, Government of Pakistan, in collaboration with UNESCO, initiated the School Health Program which identified 34 million students of age 5 to 24 enrolled in 228,304 educational institutions of Pakistan in dire need of 
adequate school health facilities. ${ }^{6}$

The 'Living Library' concept is an emerging trend around the globe to bridge the gap between human experiences and communication. ${ }^{7}$ In this study the concept of 'Living Book Series' was incorporated. Live verbal communication was used as a tool for receiving feedback of the various incidents encountered by students themselves regarding healthcare management at school, which not only provided an insight into the situation at hand but also gave us a better understanding of the situation and highlighted the gaps between delivery, receiving and implementation of healthcare services at schools. In addition, differences in healthcare facilities and their implementation between private schools and public schools was also highlighted. These results can be used by schools to analyze their healthcare systems and continue to improve their efforts in attaining optimum health for their students.

\section{METHODS}

This was a cross sectional study conducted on 50 students of 10 identified schools of Lahore. Students of classes 6-10, only students experiencing any form of injury or illness during schools hours were included in the study. 25 students each from public and private schools were selected.

Data was collected with the help of a pre tested questionnaire after taking consent. In depth interviews were conducted by investigators. Response rate was $100 \%$. In the questionnaire both closed and open ended questions were used. In addition to demographic data, open ended questions were used to record the experiences of student with special focus on the first aid patterns, delivery and facilities available in their respective schools.

Data was analyzed using the SPSS version 17 . Frequencies and percentages were calculated.

\section{RESULTS}

In a total of 50 students 28 (56\%) were males and $22(44 \%)$ were females with a mean age of $13.9( \pm 1.46) \mathrm{yrs}$. The in depth interviews revealed the experiences of students after injuries/illness in school. All students were given first aid immediately, mostly by the teachers as most of the schools did not have trained health professionals and sick rooms. In case of severe injuries / illness parents were informed, only a few schools referred the students to a health facility. Majority of the students were satisfied with the facilities available at school in case if injuries or illnesses.

Occurrence of injury or illness during school was significant especially in the age group targeted by the study. Fractures and joint locations being the most frequently occurring injuries $15(30 \%)$ and fever being the most prevalent illness 19 (38\%)

Majority, 41(82\%) were managed at schools with a first aid facility and provision of sick rooms 28 (56\%). Teachers were the main healthcare providers in private schools 17 (34\%), as compared to public schools 9 (18\%). Lack of properly trained health professionals was observed; only 5 out of 50 schools had employed nurses. Health education regarding hand washing, personal hygiene, and dengue prevention was being provided in 45 (90\%) schools.

Only 28 (56\%) of the schools arranged health checkups on a weekly, half-yearly or yearly basis. Out of a total of 50 students, $33(66 \%)$ rated the quality of care provided as good, the rest thought of it as average or poor.

\begin{tabular}{|c|c|c|c|}
\hline Sr. \# & $\begin{array}{c}\text { Health Care } \\
\text { Providers }\end{array}$ & $\begin{array}{c}\text { Public } \\
\text { Schools } \\
\mathbf{n = 2 5}\end{array}$ & $\begin{array}{c}\text { Private } \\
\text { Schools } \\
\mathbf{n = 2 5}\end{array}$ \\
\hline 1 & Nurse & $3(10.7 \%)$ & $2(9.1 \%)$ \\
\hline 2 & Doctor & $10(35.7 \%)$ & $0(0 \%)$ \\
\hline 3 & Teacher & $9(32.1 \%)$ & $17(77.3 \%)$ \\
\hline 4 & Dispenser & $6(21.4 \%)$ & $3(13.6 \%)$ \\
\hline 5 & Total & $28(100 \%)$ & $22(100 \%)$ \\
\hline
\end{tabular}

Table-I. Distribution of students according to officials who provided first aid at public and private schools of Lahore 


\begin{tabular}{|c|c|c|}
\hline Sr. \# & Healthcare Facilities & $\begin{array}{c}\text { School } \\
\mathbf{n = 5 0}\end{array}$ \\
\hline 1 & $\begin{array}{c}\text { First aid management of } \\
\text { injured /ill students }\end{array}$ & $41(82 \%)$ \\
\hline 2 & Provision of sick rooms & $28(56 \%)$ \\
\hline 3 & Employed nurses & $5(14 \%)$ \\
\hline 4 & Health education & $45(90 \%)$ \\
\hline
\end{tabular}

Table-II. Distribution of healthcare facilities provided at schools of Lahore:

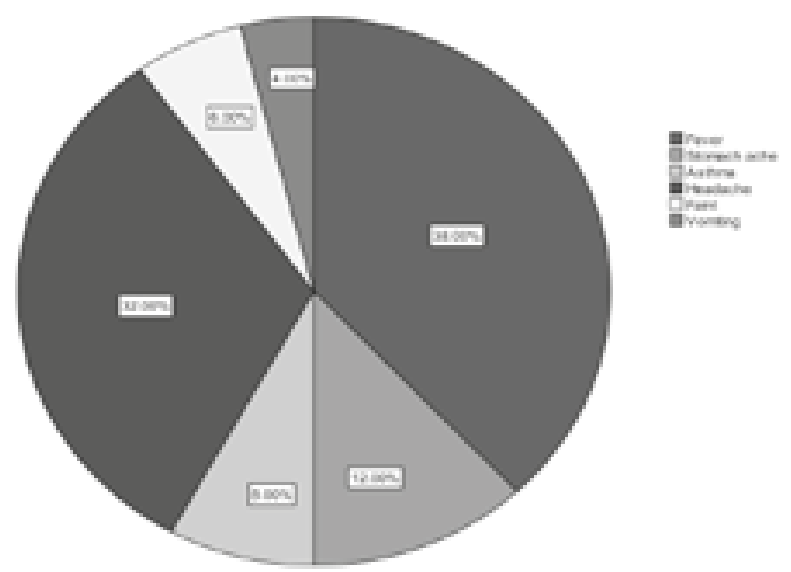

Figure-1. Graphical representation of distribution of illnesses in schools of Lahore

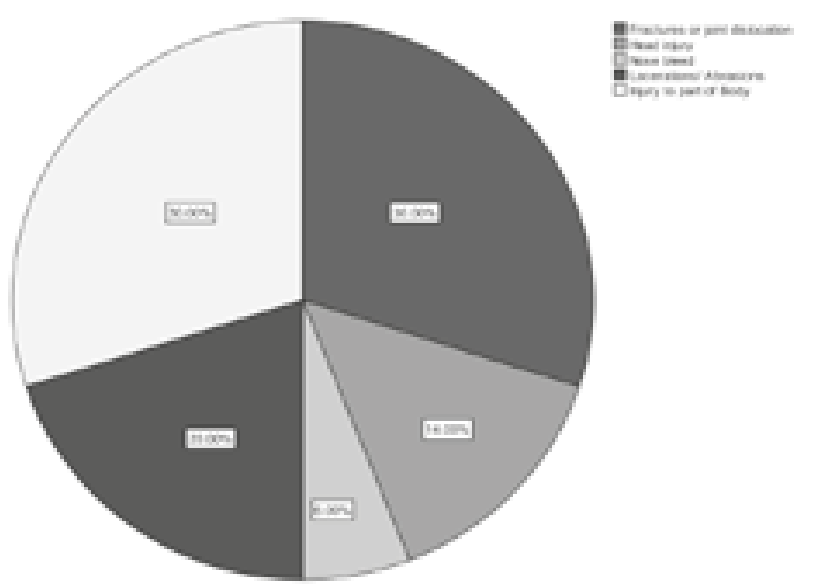

Figure-2. Graphical representation of distribution of injuries in schools of Lahore

\section{DISCUSSION}

As children spend a good part of their day in school, they are liable to suffer from some kind of injury or illness. To deal with everyday emergencies, to detect communicable and non-communicable diseases earlier on and identify major issues regarding a child's health an essential healthcare system in school is required. ${ }^{8}$

The current study has been conducted with the objective to assess the experiences of students regarding healthcare management especially first aid patterns at private and public schools of Lahore, Pakistan.

In our study it was observed that percentage of teachers performing these duties was greater in private schools than in public schools. $45.5 \%$ of the injuries in private schools compared to $28.6 \%$ in government schools (chi square 4.971, p-value 0.174). $77.3 \%$ of the illnesses in private schools compared to $32.1 \%$ in government schools (chi square 13.13, p-value 0.004) were being managed by teachers. The potential of a trained teacher can be exploited to promote health care and related activities in third world countries. ${ }^{9}$

It was observed that fractures and joint dislocations in females (36.4\%) as compared to males (25\%), (chi square 3.753 p-value 0.44 ) and fever in females $(31.8 \%)$ as compared to males (42.9\%), (chi square1.619, p-value 0.899) were the most common injury and illness. Studies conducted in different schools around the world also corroborate with our results, cold and fever being the most frequently faced illness in school age children ${ }^{10,11}$, and fractures being one of the most suffered from injury. ${ }^{11}$

Majority of the students (90\%) gave a positive feedback regarding the provision of health education for common illnesses prevalent in our country which is supported by a study "Fit for school", conducted in Philippines, that showed that with minimal cost high benefits can be achieved with health education, the incidence of diarrhea and respiratory infections was reduced by $30 \%-50 \%{ }^{6}$

This study concluded that health facilities being provided at schools should be more comprehensive and focused. Teachers should be trained as they were found to be the main 
respondents in case of injury or illness to the students. The school health program that exists should be implemented not only in public but also in private schools.

\section{RECOMMENDATIONS}

1. Provision of first aid services with proper allocation of place that is sick rooms should be ensured in schools to combat with injuries or illnesses to students during school timings.

2. Ideally, there should be a visiting medical officer. In all cases teachers should be provided with BLS and first aid training in order to pertain to emergency situations.

3. Schools should carry out annual or six-monthly health screenings (medical checkups) as specified in the school health program.

4. Proper referral system should exist where students are referred with the involvement of the parents.

5. Promotion of health awareness programs should be conducted by the school with the involvement of students, teachers, parents and members of the community.

6. Implementation of school health program should be ensured by the government in both private and public schools.

Copyright@ 04 Nov, 2015.

\section{REFERENCES}

1. Basch EC. Healthier students are better learner: A mission link in school reforms to close the achievement gap. Equity Matters. 2010 Mar; 6.

2. Small ML, Majer LS, Allensworth DD, Farquhar BK, Kann L, Pateman BC. School health services. J School Health. 1995.

3. www.who.int/school_youth_health/gshi/hps/en.

4. www.schoolsandhealth.org.

5. http://www.nchd.org.pk/ws/index.php?option=com content\&view $=$ article\&id $=65 \&$ ltemid $=33$.

6. School health program: A strategic approach for improving health and education in Pakistan.2010 Feb.

7. humanlibrary.org/what-is-the-living-library.html

7. Ahmad F, Danish HS, School Health services, a neglected sphere of influence in Pakistan. Journal of Pakistan Medical Association. 2013 Aug.

9. Haleem A, Khan AA. School bases oral health education in Pakistan- The need and possible strategies. Pakistan Oral and Dental Journal. 2006 Jun; 26(1)

10. Lewis S. Common illnesses and injuries in schools.

11. Arca M, 5 common back to school illnesses.

\section{AUTHORSHIP AND CONTRIBUTION DECLARATION}

\begin{tabular}{|c|c|c|c|}
\hline Sr. \# & Author-s Full Name & Contribution to the paper & Author $=\mathbf{s}$ Signature \\
\hline 1 & Dr. Naureen Omar & $\begin{array}{l}\text { Concept, questionnaire } \\
\text { development, refinement }\end{array}$ & \\
\hline 2 & Rameeshey Khan & $\begin{array}{l}\text { Questionnaire } \\
\text { development, Discussion }\end{array}$ & aney - \\
\hline 3 & Faizan Farooq & Results, Analysis & Farzan \\
\hline 4 & Humera Karim & Literature review & \\
\hline 5 & Muhammad Ayoub & $\begin{array}{l}\text { Data entry analysis } \\
\text { refinement of results }\end{array}$ & A \\
\hline 6 & Ushna Habib & Introduction & Manne. \\
\hline
\end{tabular}

